\title{
Mecanismo de mutagênese de SARS-CoV-2 induzida pelo molnupiravir e resultados desse antiviral em pacientes acometidos por COVID-19
}

Molnupirvir-induced SARS-CoV-2 mutagenesis mechanism and results of this antiviral in patients affected by COVID-19

Mecanismo de mutagénesis del SARS-CoV-2 inducido por molnupirvir y resultados de este antiviral en pacientes afectados por COVID-19

\section{Resumo}

Introdução: Os medicamentos antivirais frequentemente têm como alvo as polimerases virais e funcionam como análogos de nucleosídeos que terminam o alongamento da cadeia de RNA. No entanto, tais antivirais de terminação de cadeia geralmente não são eficazes contra SARS-CoV-2, haja vista que os coronavírus carregam uma atividade de revisão exonucleolítica, que pode, desse modo, remover nucleotídeos incorporados incorretamente das extremidades de RNAs. Objetivo: elucidar os mecanismos mutagênicos de SARS-CoV-2 induzidos pelo molnupiravir, bem como de acoplar os resultados do uso desse antiviral em pacientes acometidos por COVID-19. Metodologia: Trata-se de uma revisão sistemática de literatura e foi realizado o cruzamento dos descritores, em inglês: "molnupiravir", "COVID-19", "SARS-CoV-2", "antiviral", "RNA" nas seguintes bases de dados: National Library of Medicine (PubMed MEDLINE), Scientific Electronic Library Online (Scielo), Cochrane Database of Systematic Reviews (CDSR), Google Scholar, Biblioteca Virtual em Saúde (BVS) e EBSCO Information Services. Foram analisadas fontes relevantes inerentes ao tema, utilizando como um dos principais critérios a escolha de artigos atuais, originais e internacionais. Após leitura criteriosa das publicações, 4 artigos não foram utilizados devido aos critérios de exclusão. Assim, totalizaram-se 12 artigos científicos para a revisão. Resultados: O molnupiravir ou NHC pode aumentar as mutações de transição $\mathrm{G}$ para A e C para U na replicação dos coronavírus. Esses aumentos nas frequências de mutação podem estar associados a aumentos nos efeitos antivirais; no entanto, não foram relatados dados bioquímicos de mutagênese induzida por molnupiravir. Aqui nós estudamos os efeitos do composto ativo NHC 5'-trifosfato (NHCTP) contra o complexo purificado da síndrome respiratória aguda grave do coronavírus 2 RNA polimerase dependente de RNA. Além disso, o molnupiravir demonstrou atividade in vitro contra a síndrome respiratória aguda grave coronavírus 2 (SARS-CoV-2) em culturas de células epiteliais das vias aéreas humanas. Conclusão: um candidato promissor para o tratamento desses pacientes é o molnupiravir (ou EIDD-2801), que também tem como alvo RdRp de SARS-CoV-2, interfere na replicação do vírus, inibindo a replicação do SARS-CoV-2 no tecido pulmonar humano e bloqueando sua transmissão.

Palavras-chave: SARS-CoV-2; COVID-19; Antiviral; Molnupiravir.

\begin{abstract}
Introduction: Antiviral drugs often target viral polymerases and function as nucleoside analogues that terminate the elongation of the RNA chain. However, such chain-terminating antivirals are generally not effective against SARS$\mathrm{CoV}-2$, as coronaviruses carry an exonucleolytic proofreading activity, which can thus remove improperly incorporated nucleotides from the ends of RNAs. Objective: to elucidate the mutagenic mechanisms of SARS-CoV-2 induced by molnupirvir, as well as to couple the results of the use of this antiviral in patients affected by COVID- 19 . Methodology: This is a systematic literature review and the following keywords were crossed: "molnupiravir", "COVID-19", "SARS-CoV-2", "antiviral", "RNA" in the following bases data: National Library of Medicine (PubMed MEDLINE), Scientific Electronic Library Online (Scielo), Cochrane Database of Systematic Reviews
\end{abstract}


(CDSR), Google Scholar, Virtual Health Library (VHL) and EBSCO Information Services. Relevant sources inherent to the theme were analyzed, using as one of the main criteria the choice of current, original and international articles. After careful reading of the publications, 4 articles were not used due to the exclusion criteria. Thus, there were a total of 12 scientific articles for review. Results: Molnupiravir or NHC can increase G to A and C to U transition mutations in coronavirus replication. These increases in mutation frequencies may be associated with increases in antiviral effects; however, no biochemical data of molnupirvir-induced mutagenesis have been reported. Here we study the effects of the active compound NHC 5'-triphosphate (NHC-TP) against the purified severe acute respiratory syndrome coronavirus 2 RNA-dependent RNA polymerase complex. In addition, molnupiravir has demonstrated in vitro activity against the severe acute respiratory syndrome coronavirus 2 (SARS-CoV-2) in cultures of human airway epithelial cells. Conclusion: a promising candidate for the treatment of these patients is molnupiravir (or EIDD-2801), which also targets RdRp of SARS-CoV-2, interferes with virus replication, inhibiting SARS-CoV-2 replication in tissue human lung and blocking its transmission.

Keywords: SARS-CoV-2; COVID-19; Antiviral; Molnupiravir.

\section{Resumen}

Introducción: Los medicamentos antivirales a menudo se dirigen a las polimerasas virales y funcionan como análogos de nucleósidos que terminan el alargamiento de la cadena de ARN. Sin embargo, tales antivirales de terminación de cadena generalmente no son efectivos contra el SARS-CoV-2, ya que los coronavirus llevan una actividad de corrección de pruebas exonucleolítica, que por lo tanto puede eliminar los nucleótidos incorporados incorrectamente de los extremos de los ARN. Objetivo: dilucidar los mecanismos mutagénicos del SARS-CoV-2 inducido por molnupirvir, así como acoplar los resultados del uso de este antiviral en pacientes afectados por COVID-19. Metodología: Se trata de una revisión sistemática de la literatura y se cruzaron las siguientes palabras clave: "molnupiravir", "COVID-19", "SARS-CoV-2", "antiviral", "RNA" en las siguientes bases de datos: Biblioteca Nacional de Medicina (PubMed MEDLINE), Scientific Electronic Library Online (Scielo), Cochrane Database of Systematic Reviews (CDSR), Google Scholar, Virtual Health Library (BVS) y EBSCO Information Services. Se analizaron fuentes relevantes inherentes a la temática, utilizando como uno de los principales criterios la elección de artículos actuales, originales e internacionales. Tras una lectura atenta de las publicaciones, 4 artículos no se utilizaron debido a los criterios de exclusión. Así, hubo un total de 12 artículos científicos para revisión. Resultados: Molnupiravir o NHC pueden aumentar las mutaciones de transición de G a A y C a U en la replicación del coronavirus. Estos aumentos en la frecuencia de mutaciones pueden estar asociados con aumentos en los efectos antivirales; sin embargo, no se han informado datos bioquímicos de mutagénesis inducida por molnupirvir. Aquí estudiamos los efectos del compuesto activo NHC 5'-trifosfato (NHC-TP) contra el complejo de ARN polimerasa dependiente de ARN del coronavirus 2 del síndrome respiratorio agudo grave purificado. Además, molnupiravir ha mostrado actividad in vitro contra el síndrome respiratorio agudo severo coronavirus 2 (SARS-CoV-2) en cultivos de células epiteliales de las vías respiratorias humanas. Conclusión: un candidato prometedor para el tratamiento de estos pacientes es el molnupiravir (o EIDD-2801), que también se dirige a RdRp del SARS-CoV-2, interfiere con la replicación del virus, inhibe la replicación del SARS-CoV-2 en el tejido pulmonar humano y bloquea su transmisión.

Palabras clave: SARS-CoV-2; COVID-19; Antivírico; Molnupiravir.

\section{Introdução}

Os medicamentos antivirais frequentemente têm como alvo as polimerases virais e funcionam como análogos de nucleosídeos que terminam o alongamento da cadeia de RNA. No entanto, tais antivirais de terminação de cadeia geralmente não são eficazes contra SARS-CoV-2, haja vista que os coronavírus carregam uma atividade de revisão exonucleolítica, que pode, desse modo, remover nucleotídeos incorporados incorretamente das extremidades de RNAs. O primeiro medicamento aprovado pela Food and Drug Administration (FDA) para o tratamento de pacientes acometidos por COVID-19 foi o remdesivir, no entanto, sua eficácia foi contestada, enfatizando-se a necessidade de desenvolvimento de novos medicamentos antivirais (Abdelnabi et al., 2021).

Sabe-se que os coronavírus utilizam a RNA polimerase dependente de RNA (RdRp) para a replicação e transcrição de seu genoma de RNA e, por isso, a RdRp é um alvo importante nos esforços atuais de desenvolvimento de drogas para o tratamento da COVID-19. Um candidato promissor para o tratamento desses pacientes é o molnupiravir (ou EIDD-2801), que também tem como alvo RdRp de SARS-CoV-2, interfere na replicação do vírus, inibindo a replicação do SARS-CoV-2 no tecido pulmonar humano e bloqueando sua transmissão (Prainter et al., 2021). 
O molnupiravir é um antiviral de amplo espectro que é um pró-fármaco com biodisponibilidade oral do análogo de nucleosídeo $\beta$ - DN-hidroxicitidina (NHC), que é convertido para a sua forma trifosfato molnupiravir ativo (MTP) na célula e pode aumentar as mutações de transição G para A e C para U na replicação dos coronavírus. Assim, após a incorporação do molnupiravir (como o MNP monofosforilado), a síntese de RNA prossegue sem parar, o que indica que o MNP não atua como um terminador de cadeia, mas é prontamente incorporado ao p-RNA. A falta de interrupção da síntese de RNA pode mitigar o envolvimento do complexo de revisão, tornando-o incapaz de extirpar o MNP incorporado (Cox et al., 2021).

Esses aumentos nas frequências de mutação podem estar associados a aumentos nos efeitos antivirais, no entanto, não foram relatados dados bioquímicos de mutagênese induzida por molnupiravir. Em contraste aos medicamentos aprovados no primeiro semestre de 2021, como o remdesivir, que são administrados por infusão, o molnupiravir está disponível por via oral (Gordon et al., 2021). Sob essa perspectiva, o objetivo deste estudo foi de elucidar os mecanismos mutagênicos de SARSCoV-2 induzidos pelo molnupiravir, bem como de acoplar os resultados do uso desse antiviral em pacientes acometidos por COVID-19.

\section{Metodologia}

Trata-se de uma pesquisa descritiva do tipo revisão sistemática da literatura. Para a elaboração da questão de pesquisa, utilizou-se a estratégia PICOT (Acrômio para Patient, Intervention, Comparation, Outcome and Time). O uso dessa estratégia para formular a questão de pesquisa na condução de métodos de revisão possibilita a identificação de palavras-chave, as quais auxiliam na localização de estudos primários relevantes nas bases de dados. Assim, a questão de pesquisa delimitada foi: "quais os mecanismos de mutagêneses de SARS-CoV-2 induzidas pelo molnupiravir e resultados desse antiviral em pacientes acometidos por COVID-19?". Dessa maneira, compreende-se que $\mathrm{P}=$ pacientes infectados por SARS-CoV-2; $\mathrm{I}=$ pacientes com COVID-19 que utilizaram molnupiravir; $\mathrm{Co}=$ pacientes com COVID-19 que não utilizaram molnupiravir; $\mathrm{T}=$ dois meses de coleta de dados.

A partir do estabelecimento das palavras-chave da pesquisa, foi realizado o cruzamento dos descritores, em inglês: "molnupiravir", "COVID-19", "SARS-CoV-2", "antiviral", "RNA" nas seguintes bases de dados: National Library of Medicine (PubMed MEDLINE), Scientific Electronic Library Online (Scielo), Cochrane Database of Systematic Reviews (CDSR), Google Scholar, Biblioteca Virtual em Saúde (BVS) e EBSCO Information Services. A pesquisa bibliográfica foi de cunho exploratório, partindo da identificação, da seleção e da avaliação de trabalhos e de artigos científicos considerados relevantes para dar suporte teórico para a classificação, a descrição e a análise dos resultados.

A busca foi realizada nos meses de outubro e novembro 2021. Foram considerados estudos publicados no período compreendido entre 2020 e 2021. A estratégia de seleção dos artigos seguiu as seguintes etapas: busca nas bases de dados selecionadas; leitura dos títulos de todos os artigos encontrados e exclusão daqueles que não abordavam o assunto; leitura crítica dos resumos dos artigos e leitura na íntegra dos artigos selecionados nas etapas anteriores.

Foram analisadas fontes relevantes inerentes ao tema, utilizando como um dos principais critérios a escolha de artigos atuais, originais e internacionais. Após leitura criteriosa das publicações, 4 artigos não foram utilizados devido aos critérios de exclusão. Assim, totalizaram-se 12 artigos científicos para a revisão sistemática da literatura, com os descritores apresentados acima. Após esta seleção, filtraram-se por artigos dos últimos dois anos e por artigos em língua inglesa. Como critérios de inclusão, foram considerados artigos originais, que abordassem o tema pesquisado e permitissem acesso integral ao conteúdo do estudo, no período de 2020 a 2021, em inglês. O critério de exclusão foi imposto naqueles trabalhos que não estavam em inglês, que não tinham passado por processo de Peer-View e que não se relacionassem com o tema, conforme elucidado pela Figura 1. 
Figura 1: Etapas de seleção de artigos para esta pesquisa.
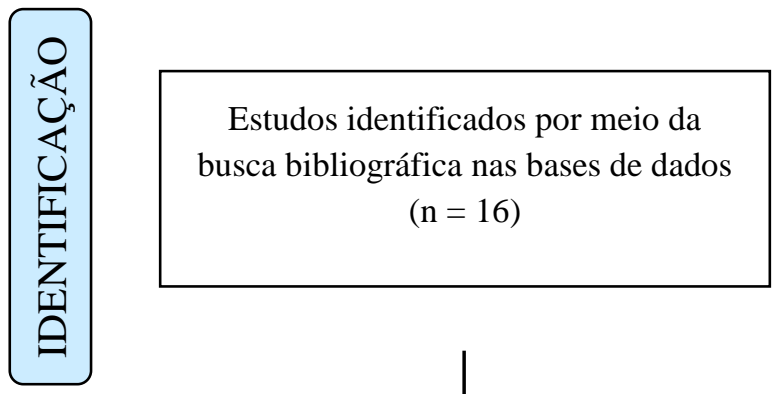

N. de relatos identificados em outras fontes $(n=0)$
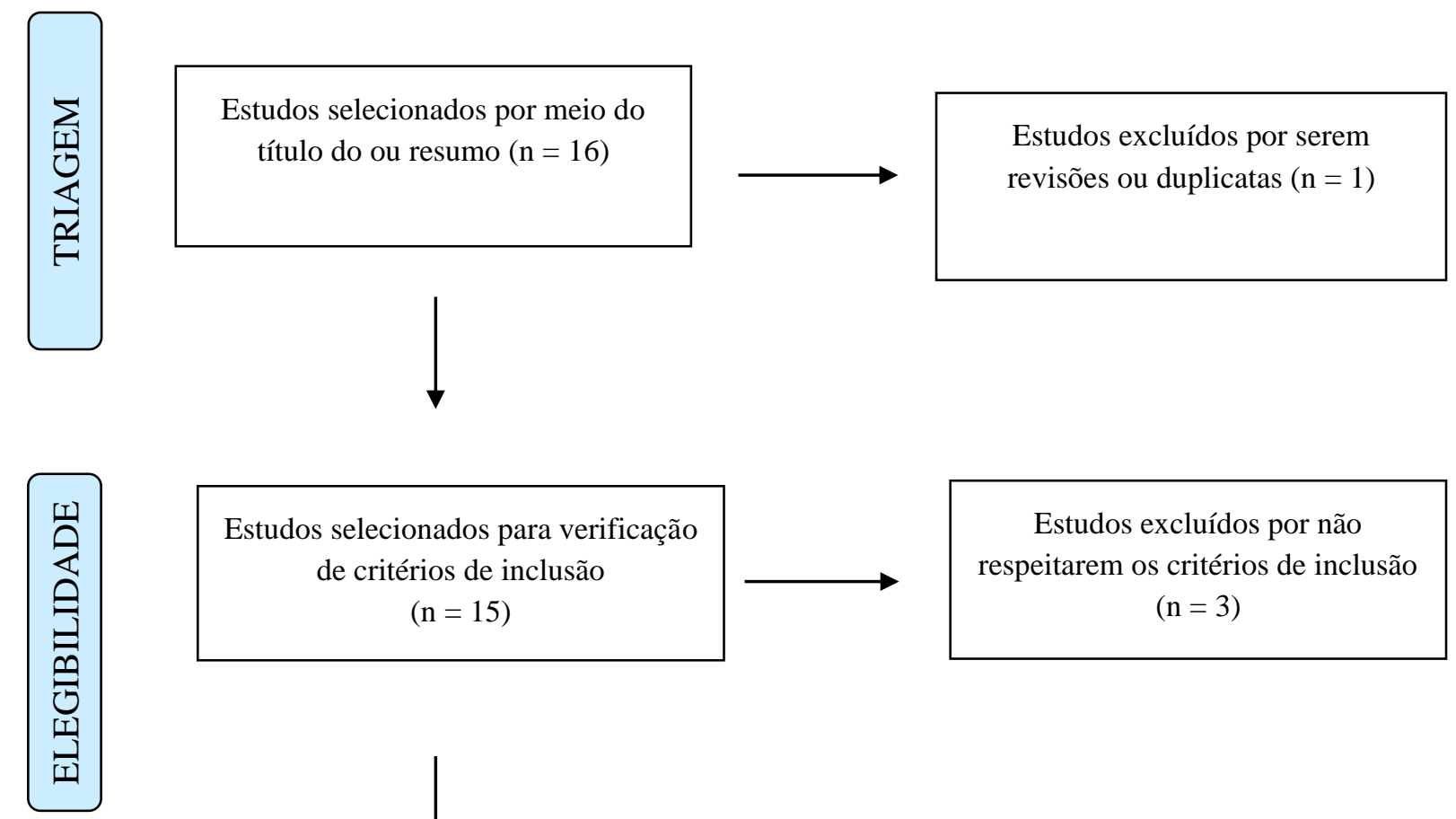

Estudos selecionados para verificação de critérios de inclusão $(\mathrm{n}=15)$

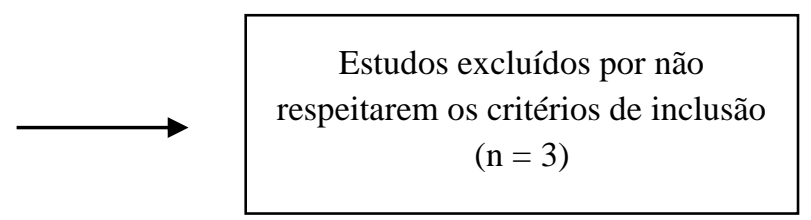

Estudos incluídos para a revisão de literatura $(n=12)$

Fonte: Autores.

\section{Resultados e Discussão}

Estudos de Kabinger et al. (2021) e Gordon et al. (2021) chegaram a conclusões semelhantes sobre o mecanismo de mutagênese letal pelo molnupiravir, com diferenças sutis. Gordon et al. (2021) enfatizaram que as mutações de transição Cpara-U ocorrem quando o MNP é incorporado na fita molde, pois os dois tautômeros de NHC existem mais igualmente do que sua forma trifosfato de substrato. Então, este modelo racionaliza os achados bioquímicos no contexto das altas frequências de mutações de transição G para A e C para U em coronavírus expostos ao molnupiravir. Outra diferença é que o modelo fornecido por Kabinger et al. (2021) considera as transições de A para G, que podem ocorrer em coronavírus expostos ao 
molnupiravir, embora em frequências muito mais baixas. Assim, mesmo que as evidências bioquímicas indiquem que o MTP é um melhor análogo do CTP, os dados genéticos sugerem que o MTP pode competir fracamente com o UTP, induzindo transições de A para G.

Em resumo, os dois estudos demonstram que a mutagênese letal induzida por molnupiravir é minimamente um mecanismo de duas etapas caracterizado por uma seletividade relativamente alta de MTP para incorporação como um análogo de CTP e a incorporação indiscriminada de ATP (mutagênese) ou GTP quando MNP é localizado na vertente templating. O AMP incorporado erroneamente pode subsequentemente modelar a incorporação de UTP, gerando mutações de C para U a jusante. Desse modo, o acúmulo de mutações empurra a replicação viral acima do "limite de erro", que demarca a fidelidade de replicação necessária para a viabilidade. Inclusive, esse mecanismo distingue o molnupiravir do remdesivir, que impede a progressão do RdRp viral e fornece informações sobre os mecanismos alternativos de inibição do RdRp (Abdelnabi et al., 2021).

No entanto, ensaios de Prainter et al. (2021), de alongamento da estrutura, mostraram que o resíduo M na posição +1 da fita molde direcionou a incorporação de $\mathrm{G}$ ou $\mathrm{A}$ no RNA nascente, mas não $\mathrm{C}$ ou U. Isso pode ser explicado pela formação de pares de bases M-GTP ou M-ATP no centro ativo RdRp. Consistente a isso, os experimentos de fusão térmica com duplexes de RNA contendo pares de bases MG ou MA, localizados em posições terminais ou internas, mostraram estabilidades de duplex de RNA semelhantes que foram ligeiramente menores do que para duplexes contendo um par de bases CG. Assim, quando o RdRp utiliza o RNA contendo monofosfato de NHC como molde, o nucleotídeo correto ou incorreto seria incorporado ao produto de RNA e, portanto, ocorreria a mutagênese.

Os dados acima indicam, então, que o aspecto chave do mecanismo de mutagênese é a formação de pares de bases estáveis MG e MA no centro ativo RdRp. Para investigar isso, analisaram duas estruturas de complexos RdRp-RNA que, correspondem aos produtos de mutagênese após a incorporação do modelo M de G ou A e formaram complexos RdRp-RNA contendo $\mathrm{M}$ na fita modelo e $\mathrm{G}$ ou A na extremidade 3 'da fita produto. Previu-se que isso resultaria na formação de pares de bases nascentes MG ou MA na posição -1, que é ocupada após incorporação de nucleotídeo com modelo M bem-sucedida e translocação RdRp. Também prepararam arcabouços de duplex de RNA com oligonucleotídeos contendo M, formaram complexos de andaime RdRp-RNA e os submeteram à análise. De fato, obtiveram estruturas RdRp-RNA que continham um par de bases MA ou MG na posição -1 (Malone et al., 2021), conforme ilustrado pela Figura 2. 
Figura 2: A) Visão geral da estrutura RdRp-RNA com um resíduo M (laranja) na posição -1 na fita modelo de RNA. As subunidades RdRp nsp7, nsp8 e nsp12 estão em azul escuro, verde e cinza, respectivamente. O modelo de RNA e o produto estão em azul e vermelho, respectivamente. É representada a estrutura que contém o par de bases MA. B) duplex de RNA contendo o par de bases MA no centro ativo RdRp. A posição +1 (nucleotídeo de modelagem, local do substrato NTP) e a posição -1 (posição pós-translocação do par de bases nascente) são indicadas. C) duplex de RNA contendo o par de bases MG no centro ativo RdRp. D), Densidade Cryo-EM para os pares de bases nascentes MA (topo) e MG (fundo) na posição -1, vistos ao longo do eixo do duplex de RNA na direção da translocação de RNA. E), MA (superior) e MG (inferior) depende de diferentes formas tautoméricas de NHC.

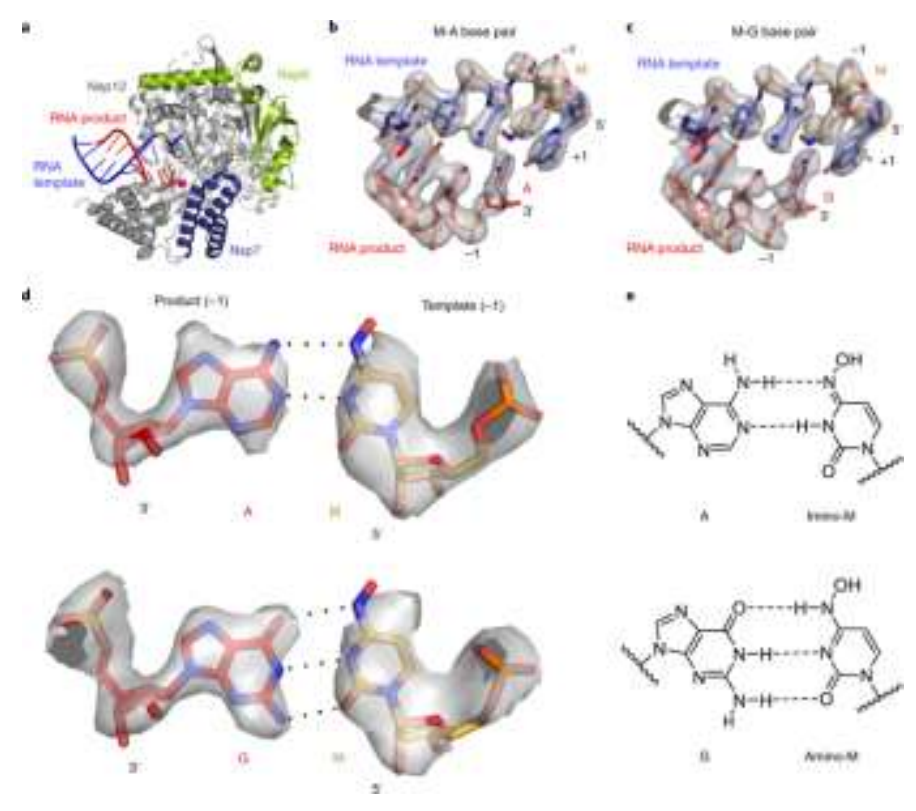

Fonte: Malone et al. (2021).

Ou seja, essa análise bioquímica sistemática sugeriu um modelo de duas etapas para o mecanismo de mutagênese de RNA de coronavírus induzida por molnupiravir (Figura 3). Quando o pró-fármaco do molnupiravir entra na célula, ele é convertido em NHC trifosfato (MTP), que pode ser usado pelo RdRp do SARS-CoV-2 como substrato em vez de CTP ou UTP. Portanto, em uma primeira etapa, o RdRp é previsto para incorporar frequentemente M em vez de C ou U quando usa o RNA genômico de fita positiva (+ gRNA) como um modelo para sintetizar o RNA genômico de fita negativa (-gRNA) e subgenômico (-sgRNA). Em uma segunda etapa, o RNA contendo M resultante pode ser usado como um modelo para a síntese de + gRNA ou mRNA subgenômico de fita positiva (+ sgmRNA). A presença de M no -gRNA leva então a mutações nos produtos de RNA de fita positiva, que não suportam a formação de novos vírus intactos, conforme previsto pelo modelo de “catástrofe de erro" (Malone et al., 2021; Prainter et al., 2021). 
Figura 3: Etapas para o mecanismo de mutagênese de RNA do SARS-CoV-2 induzida por molnupiravir.

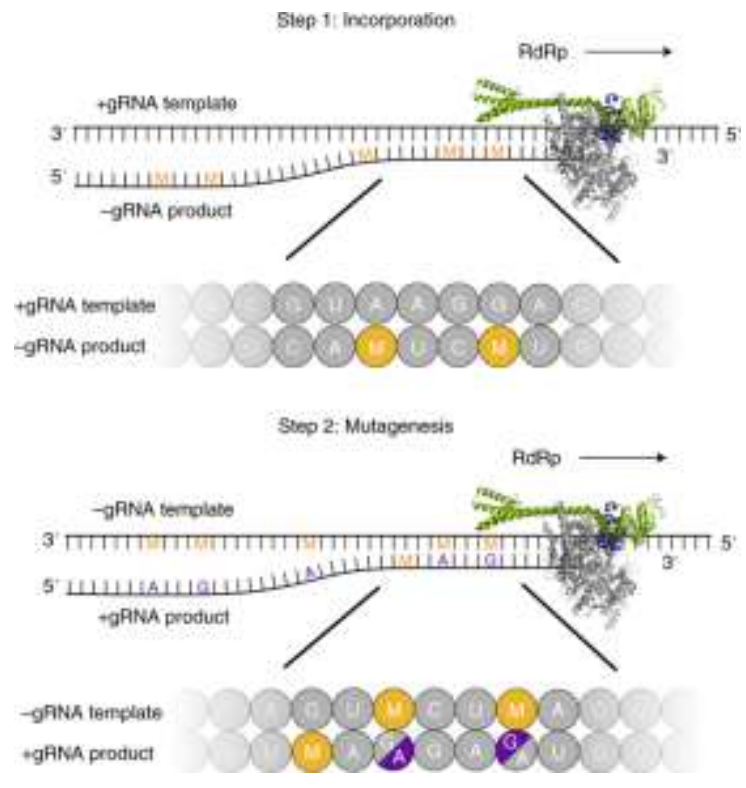

Fonte: Malone et al. (2021).

Na presença do trifosfato de nucleosídeo e MTP, os nucleotídeos M podem ser incorporados por SARS-CoV-2 RdRp, em vez de $\mathrm{C}$ ou U no genômico de fita negativa (-gRNA) ou RNA subgenômico (-sgRNA) durante a cópia do genômico de fita positiva Molde de RNA (+ gRNA). Os RNAs de fita negativa contendo M obtidos poderiam, então, ser utilziados como um modelo para a produção de mRNA + gRNA mutagenizado e de fita positiva subgenômica (+ sgmRNA). Prevê-se, desse modo, que esses produtos de RNA sofram mutação e não suportem a formação de vírus funcionais. Assim, estudos estruturais confirmam o aspecto chave deste modelo, ou seja, a formação de pares de bases MG e MA no centro ativo RdRp (Kabinger et al., 2021).

Estudos clínicos tem demostrado que o molnupiravir é rapidamente clivado no plasma em EIDD-1931, que, após distribuição em vários tecidos, é convertido em seu 5'-trifosfato correspondente pelas quinases hospedeiras, um substrato alternativo competitivo para a polimerase de RNA dependente de RNA codificada por vírus e, que, após a incorporação no RNA viral de cadeia nascente, induz um efeito antiviral por meio de uma catástrofe de erro viral, um conceito que é predicado no aumento da taxa de mutação viral além de um limite biologicamente tolerável, resultando em comprometimento da aptidão viral e levando à extinção viral (Teoh et al., 2020; Sheahan et al., 2020).

Ademais, o molnupiravir demonstrou atividade in vitro contra a síndrome respiratória aguda grave coronavírus 2 (SARS-CoV-2) em culturas de células epiteliais das vias aéreas humanas. A administração profilática e terapêutica de molnupiravir a camundongos infectados com coronavírus da síndrome respiratória aguda grave (SARS-CoV-2) ou coronavírus da síndrome respiratória do Oriente Médio (MERS-CoV) melhorou a função pulmonar e reduziu a virulência do vírus (Cox et al., 2021). Desse modo, o Quadro 1 demonstra os principais achados de estudos observacionais e de campo, acerca da eficácia do medicamento em pacientes sob espectro da COVID-19. 
Quadro 1: Principais achados dos estudos acerca da eficácia do molnupiravir sob o SARS-CoV-2.

\begin{tabular}{|l|c|l|}
\hline \multicolumn{1}{|c|}{ AUTORES } & ANO & \multicolumn{1}{c|}{ RESULTADOS } \\
\hline Prainter et al. & 2021 & $\begin{array}{l}\text { O tratamento com molnupiravir resultou em uma redução estatisticamente significativa nas cópias de } \\
\text { RNA viral por mg de tecido pulmonar e reduziu significativamente os títulos pulmonares do vírus } \\
\text { infeccioso, independentemente da variante SARS-CoV-2. }\end{array}$ \\
\hline Sheahan et al. & 2021 & $\begin{array}{l}\text { Houve melhora significativa dos escores pulmonares histopatológicos cumulativos também foi } \\
\text { observada em todos os grupos tratados com molnupiravir com uma redução dos escores médios da } \\
\text { doença. }\end{array}$ \\
\hline Abdelnabi et al. & 2021 & $\begin{array}{l}\text { O molnupiravir melhorou a histopatologia dos pulmões de hamsters sírios infectados com diferentes } \\
\text { variantes do SARS-CoV-2. }\end{array}$ \\
\hline Gordon et al. & 2021 & $\begin{array}{l}\text { O medicamento oral experimental da MSD contra a COVID-19, o molnupiravir, reduziu em cerca de } \\
50 \% \text { chance de hospitalização ou morte em pacientes sob risco de doença grave. }\end{array}$ \\
\hline Mehase et al. & 2021 & $\begin{array}{l}\text { O molnupiravir reduziu o risco de internação hospitalar ou morte em todos os subgrupos principais, } \\
\text { com eficácia não afetada pelo momento do início dos sintomas, fatores de risco subjacentes ou tipo de } \\
\text { variante (gama e delta). }\end{array}$ \\
\hline Sheahan et al. & 2021 & $\begin{array}{l}\text { O medicamento demonstrou inibir as propagações dos vírus: SARS-CoV, MERS-CoV e SARS-CoV-2, } \\
\text { reforçando seu perfil inibitório coronaviral. }\end{array}$ \\
\hline
\end{tabular}

Fonte: Dados da pesquisa (2021).

A capacidade do molnupiravir de potencialmente tratar infecções por vírus de RNA respiratório altamente patogênico foi demonstrada em modelos de doença e altamente eficaz no tratamento de infecções sazonais e pandêmicas de influenza e no bloqueio da transmissão da SARS-CoV-2. As doses totalmente eficazes mais baixas foram 2,3 mg / $\mathrm{kg}$ de peso corporal contra a gripe sazonal e $7 \mathrm{mg} / \mathrm{kg}$ de peso corporal contra a gripe pandêmica. Além disso, uma dose terapêutica de $5 \mathrm{mg} / \mathrm{kg}$ foi completamente eficaz no bloqueio da transmissão da SARS-CoV-2 de animais infectados que liberam o vírus para animais não infectados em coabitação (Naydenova et al., 2021; Mehase et al., 2021).

Ademais, o molnupiravir também foi altamente eficaz quando administrado profilaticamente e terapeuticamente em modelos de ratos SARS-CoV-2 e MERS-CoV. Doses de 50, 150 e $500 \mathrm{mg} / \mathrm{kg}$ foram eficazes na redução significativa da carga viral pulmonar e na melhora da função pulmonar. Também é bem absorvido após a administração oral e a absorção é minimamente afetada pela ingestão de alimentos. Outrossim, muito pouco molnupiravir ou EIDD-1931 foi detectado na urina, apesar do fato de que análogos de nucleosídeos, bem como nucleosídeos naturais, são, em geral, secretados ativamente pelos rins (Zhou et al., 2021; Malone et al., 2021).

\section{Conclusão}

Há uma necessidade significativa de um medicamento antiviral contra o SARS-CoV-2, com potencial pandêmico, que geralmente seja seguro e bem tolerado e possa ser facilmente administrado em ambulatório. A via oral de administração do molnupiravir torna-o apropriado e conveniente para administração em pacientes ambulatoriais, bem como mostrou-se seguro e eficaz na redução do risco de hospitalização e morte em pessoas com COVID-19 leve a moderado que apresentam risco aumentado de desenvolver doença grave. No entanto, apesar de parecer promissor, além de atrapalhar o processo de cópia do vírus, parece ser capaz de interferir na transcrição do código genético humano, o que poderia causar mutações no DNA. Por isso, ao optar por oferecer o medicamento aos animais por via oral, não foi observado aumento nas taxas de mutações.

\section{Referências}

Abdelnabi, R., et al. (2021). O tratamento combinado de mulnupiravir e favipiravir resulta em potenciação marcada da eficácia antiviral em um modelo de infecção de hamster SARS-CoV-2. bioRxiv, 1-4.

Cox, R. M., et al. (2021). O análogo de ribonucleosídeo administrado terapeuticamente MK-4482 / EIDD-2801 bloqueia a transmissão de SARS-CoV-2 em furões. Nat. Microbiol., 6 (7), 11-18.

Gordon, C. J., et al. (2021). Molnupiravir promove SARS-CoV-2 mutagenesis via o RNA template. J Biol Chem, 297 (8), $177-187$.

Kabinger, F., et al. (2021). Mecanismo de mutagênese de SARS-CoV-2 induzida por molnupiravir. Struct Mol Biol., 28 (9), $740-746$ 
Research, Society and Development, v. 10, n. 15, e231101522916, 2021

(CC BY 4.0) | ISSN 2525-3409 | DOI: http://dx.doi.org/10.33448/rsd-v10i15.22916

Malone, B., et al. (2021). Molnupiravir: codificação para catástrofe. Nature Structural \& Molecular Biology, 28 (7), 706-708.

Mehase, E., et al. (2021). Molnupiravir reduz o risco de admissão hospitalar em 50\% em pacientes em risco. The BMJ, 375 (22), 1-4.

Naydenova, K., et al. (2021). Estrutura da RNA polimerase dependente de RNA da SARS-CoV-2 na presença de favipiravir-RTP. Proc. Nat Acad. Sci., 118 (20), 1-17.

Prainter W. P., et al. (2021). Segurança humana, tolerabilidade e farmacocinética do molnupiravir, um novo agente antiviral oral de amplo espectro com atividade contra SARS-CoV-2. Química de agentes antimicrobianos, 65 (48), 1-10.

Prainter, W. P., et al. (2021). Redução de SARS-CoV-2 infeccioso no estudo de tratamento de COVID-19 com molnupiravir. Retroviruses and Opportunistic Infections, $6(10), 1-5$.

Sheahan, T. P., et al. (2020). Um antiviral de amplo espectro com biodisponibilidade oral inibir o SARS-CoV-2 em culturas de células epiteliais das vias aéreas humanas e múltiplos coronavírus em camundongos. Sci Med., 12 (8), 1-6.

Teoh, S. L., et al. (2020). Antivirais de ação direta para COVID-19. Frontiers in Microbiology, 11 (18), 57-71.

Zhou, S., et al. (2021). $\beta$ - D - $\mathrm{N}^{4}$-hidroxicitidina (NHC) inibe SARS-CoV-2 por mutagênese letal, mas também é mutagênico para células de mamíferos. $J$. Infect. Dis., 224 (3), 9-13. 